\title{
Wind measurements using a LIDAR on a buoy
}

\author{
Medições do vento com um LIDAR sobre uma bóia
}

\author{
Felipe Barros Nassif ${ }^{1}$ (D), Felipe Mendonça Pimenta ${ }^{2}$ (D), Arcilan Trevenzoli Assireu ${ }^{3}$ (D), Carla de Abreu D’Aquino ${ }^{4}$ (D) \\ \& Julio César $\operatorname{Passos}^{5}$ (D) \\ ${ }^{1}$ Programa de Pós-graduação em Engenharia Mecânica, Universidade Federal de Santa Catarina, Florianópolis, SC, Brasil \\ 2Programa de Pós-graduação em Oceanografia, Universidade Federal de Santa Catarina, Florianópolis, SC, Brasil \\ ${ }^{3}$ Instituto de Recursos Naturais, Universidade Federal de Itajubá, Itajubá, MG, Brasil \\ ${ }^{4}$ Programa de Pós-graduação em Energia e Sustentabilidade, Universidade Federal de Santa Catarina, Araranguá, SC, Brasil \\ ${ }^{5}$ Programa de Pós-graduação em Engenharia Mecânica, Universidade Federal de Santa Catarina, Florianópolis, SC, Brasil \\ E-mails: felipebnassif@gmail.com (FBN), felipe.pimenta@ufsc.br (FMP), arcilan@unifei.edu.br (ATA), carla.daquino@ufsc.br (CAD), julio. \\ passos@ufsc.br (JCP)
}

Received: May 12, 2020 - Revised: July 31, 2020 - Accepted: August 06, 2020

\begin{abstract}
LIDAR technology is a promising alternative for the measurement of winds, requiring less maintenance and lower costs than meteorological towers. They are capable of remotely profiling winds by means of an infrared laser, which is backscattered by aerosols and particles carried by the air. The LIDAR can be assembled on fixed or mobile platforms. When installed on platforms such as moored buoys, the motion caused by waves must be evaluated and corrected. This study describes the use of a mechanical system and analytical methods for the motion compensation of a buoy-mounted LIDAR. A 24-hour experiment was conducted on Furnas Hydroelectric Reservoir to test the mechanical system, evaluate residual motions, and assess the winds. Correction algorithms for the horizontal wind speeds were applied using pitch and roll measurements, provided by an inertial sensor. Analyses demonstrate that horizontal wind speed errors are negligible for buoy inclinations of less than 20 degrees. The buoy-mounted LIDAR represents an economical solution for wind profiling and resource assessment of aquatic environments.
\end{abstract}

Keywords: Floating platforms; LIDAR; Remote sensing; Wind energy; Hydroelectric reservoirs.

\section{RESUMO}

A tecnologia LIDAR é uma alternativa promissora para a medição de ventos, exigindo menor manutenção e custos que as torres meteorológicas. Estes equipamentos são capazes de medir perfis do vento através de um laser infravermelho, o qual é retroespalhado por aerossóis e partículas transportadas pelo ar. O LIDAR pode ser montado em plataformas fixas ou móveis. Quando instalado em plataformas como bóias fundeadas, o movimento causado pelas ondas deve ser avaliado e corrigido. Este estudo descreve o uso de um sistema mecânico e métodos analíticos para a compensação de movimento de um LIDAR montado em uma bóia. Um experimento de 24 horas foi realizado no Reservatório Hidroelétrico de Furnas para testar o sistema de estabilização, avaliar movimentos residuais e analisar os ventos. Algoritmos de correção das velocidades horizontais do vento foram aplicados usando medições de arfagem e rolagem, fornecidas por um sensor inercial. As análises demonstram que os erros de velocidade horizontal do vento são insignificantes para inclinações de bóia inferiores a 20 graus. O LIDAR montado em bóia representa uma solução econômica para perfilagem dos ventos e avaliação de recursos eólicos em ambientes aquáticos.

Palavras-chave: Plataforma flutuante; LIDAR; Sensoriamento remoto; Energia eólica; Reservatórios hidrelétricos. 


\section{INTRODUCTION}

Offshore wind energy relates to the use of wind turbines installed over bodies of water, including lakes, reservoirs, bays and the continental shelf for the generation of electrical power. Winds are generally higher and steadier over these environments, what results in turbines operating at larger capacity factors (Pryor \& Barthelmie, 2001; Garvine \& Kempton, 2008; Assireu et al., 2011; Rodrigues et al., 2015).

Identifying the wind resource at any particular region requires accurate investigation over a period of at least two years. In order to be reliable, winds need to be monitored at the turbine hub height. Meteorological masts in the ocean require high construction and maintenance costs that vary from US $\$ 2.5$ to 15 million depending on the water depth (Wissemann, 2009; Standridge et al., 2012; Mathisen, 2013; Howe, 2014; Hsuan et al., 2014). In Europe, measurements that used to be carried out by meteorological masts are now performed with the LIDAR technology, which stands for "Light Detection and Ranging" (Hasager et al., 2013; Hasager, 2014; Peña Diaz et al., 2009, 2012). Such equipment accurately estimates the wind's speed and direction by measuring the frequency shift of the laser reflected by particles and aerosols transported by the wind (Pitter et al., 2013; Cariou, 2013). With the emergence of LIDAR, different studies have proposed the development of measuring systems for floating platforms.

LIDAR technology was applied in Muskegon Lake, as a preliminary test for the Lake Michigan observational system (Standridge et al., 2012). An onshore LIDAR was compared to a LIDAR mounted on a floating buoy moored in the sheltered waters of Hsing-Da Harbor, in the south of Taiwan. Equipments were $320 \mathrm{~m}$ apart and their wind speed squared correlation exceeded $\mathrm{R}^{2}=0.97$ (Hsuan et al., 2014). Gottschall et al. (2014) compared a buoy-mounted LIDAR positioned $450 \mathrm{~m}$ away from the FINO1 meteorological mast of the German North Sea, obtaining an excellent squared correlation $\left(R^{2}=0.996\right)$ for wind speeds at $10 \mathrm{~min}$ averages. Tests for different inclinations compared favorably a LIDAR with a $91 \mathrm{~m}$ tower at Pershore in the United Kingdom (Mangat et al., 2014). Yamaguchi \& Ishihara (2015) developed a data correction algorithm using inertial sensors integrated with a GPS for a buoy in the Fukushima offshore park, demonstrating that errors increase for large buoy motions. A LIDAR wind profiler was installed on a buoy in the Norwegian Sea and compared with a reference LIDAR located $3.5 \mathrm{~km}$ over land resulting in $\mathrm{R}^{2}=0.93$ (Mathisen, 2013).

Some of these studies motivated the development of commercial prototypes in support to the wind industry. AXYS Technology developed the FLIDAR WindSentinel, that allows the installation of two Zephir 300 LIDAR profilers in a buoy. Similar systems are commercialized by EOLOS, AWS Truepower, FUGRO and SeaRoc (Table 1). EOLOS has a LIDAR integrated into a $1 \mathrm{~kW}$ solar and $1.2 \mathrm{~kW}$ wind power supply. The DeepCLIDAR uses a Windcube profiler, with measurements between 40 and $200 \mathrm{~m}$. Seawatch is in the pre-commercial phase with a Zephir 300 LIDAR. These platforms have autonomous power supply and communication systems with costs around US\$2.5 million.

Brazil has no offshore wind farms installed so far, although there are outstanding resources over the ocean (Pimenta et al. 2019) and for many hydroelectrical reservoirs (Assireu et al., 2011;
Table 1. Commercial and pre-commercial models of floating LIDAR systems.

\begin{tabular}{|c|c|c|c|}
\hline $\begin{array}{c}\text { Equipment } \\
\text { Name }\end{array}$ & Dimensions & $\begin{array}{l}\text { Power } \\
\text { Supply }\end{array}$ & Manufacturer \\
\hline FLIDAR & $6.0 \times 6.0 \mathrm{~m}$ & Solar/Wind & AXYS \\
\hline WindSentinel & Height $15 \mathrm{~m}$ & & Technologies \\
\hline EOLOS & $4.0 \times 4.0 \mathrm{~m}$ & Solar & EOLOS \\
\hline FLS200 & Height $4.5 \mathrm{~m}$ & & \\
\hline DeepCLIDAR & $\begin{array}{l}\text { Diam. } 3.0 \mathrm{~m} \\
\text { Height } 5.0 \mathrm{~m}\end{array}$ & Solar/Wind & $\begin{array}{c}\text { AWS } \\
\text { Truepower }\end{array}$ \\
\hline Seawatch & $\begin{array}{l}\text { Diam. } 2.8 \mathrm{~m} \\
\text { Height } 6.1 \mathrm{~m}\end{array}$ & Solar & FUGRO \\
\hline SeaZephir & $\begin{array}{l}6.0 \times 6.0 \mathrm{~m} \\
\text { Height } 15 \mathrm{~m}\end{array}$ & Solar & SeaRoc \\
\hline
\end{tabular}

Pimenta \& Assireu, 2015). Until January 2020, the country had six projects with environmental licensing underway at IBAMA ${ }^{1}$ for offshore wind farms off the coast of Rio Grande do Sul, Rio de Janeiro, Rio Grande do Norte, and Ceará states (Empresa de Pesquisa Energética, 2020).

The country does not have tall meteorological towers in the ocean or in hydroelectrical reservoirs. Its meteorological buoy network in the ocean is sparse and located in deeper waters, also providing records at low level ( $3.5 \mathrm{~m}$ height). Thus, a fundamental question is whether national technologies can be developed in order to provide the necessary observations for the future wind farms.

This technical note describes a low cost system for wind monitoring over sheltered waters using the LIDAR technology. To the authors' knowledge, that is the first time a buoy was developed and tested for LIDAR measurements in Brazil. The system permits the wind profile monitoring over lakes, hydroelectrical reservoirs and sheltered bays. The buoy has applications to energy, micrometeorological, air quality and weather forecast studies.

This document is organized in three remaining sections. The Methods describes the LIDAR technology, the characteristics of the buoy and of a mechanic stabilization system, built to reduce the effects of wave motion. The field campaign and the algorithm used to treat residual buoy motions are also described. The third section presents the Results, along with a description of the wind observations. The last section provides a Summary and Conclusions.

\section{METHODS}

This section presents a description of the equipment, methods and experimental setup. The first subsection describes the LIDAR technology, the passive mechanical system of stabilization and the floating platform. The following subsections present the data correction algorithm and details of the measurement campaign.

\section{Zephir LIDAR}

A Zephir 300 LIDAR was used in the measurement campaign. The equipment measures the wind by detecting the Doppler shift of the infrared laser scattered by moving particles

Brazilian Institute of the Environment and Renewable Natural Resources (IBAMA). 
(aerosols) transported by the air. The small frequency variation is perceived by a detector and processed to estimate the wind speed along the laser beam (Zephir, 2014).

Each height has its wind speed and direction estimated by the conical scanning of a continuous laser beam (Figure 1). The VAD (Velocity Azimuth Display) scanning consists of the beam's emission at a constant elevation angle $(\theta)$ with a variable azimuth angle $(\varphi)$ (Weitkamp, 2006). This conical scanning is obtained by the rotation of a deflector prism (see inserted photo in Figure 1). Each azimuth angle is related to a wind component in the direction of the emitted ray $\vec{V}_{r}$ (radial speed). A total of 50 consecutive $\overrightarrow{V_{r}}$ measurements around the circle allow the wind velocity vector $\vec{V}$ to be determined at the center of the cone for each targeted height (Peña Diaz et al., 2009; Li \& Yu, 2017).

The emitter takes around 1 second to complete a $360^{\circ}$ azimuth scan, but nearly 17 seconds to complete a profile due to the time needed to change the focus height. The signal reflected by aerosols is sampled inside a disk of variable diameter and thickness that may reach $10 \mathrm{~m}$ (Pitter et al., 2013). The accuracy of the focus positioning of the emitted beam is ensured by the extensive inlab calibration and by automatic compensation mechanisms of possible deviations resulting from thermal expansion. Refraction effects along the beam's path are negligible. The equipment can make up to 10 wind measurements from 10 to $300 \mathrm{~m}$ heights. In this study, the target heights were programmed for $\mathrm{Z}=10$, $20,40,60,80,100,140,160,180$ and $200 \mathrm{~m}$ in reference to the reservoir water level.

\section{LIDAR mechanical stabilization}

The use of LIDARs on floating platforms faces the problem of the equipment stability. Instrument inclinations due

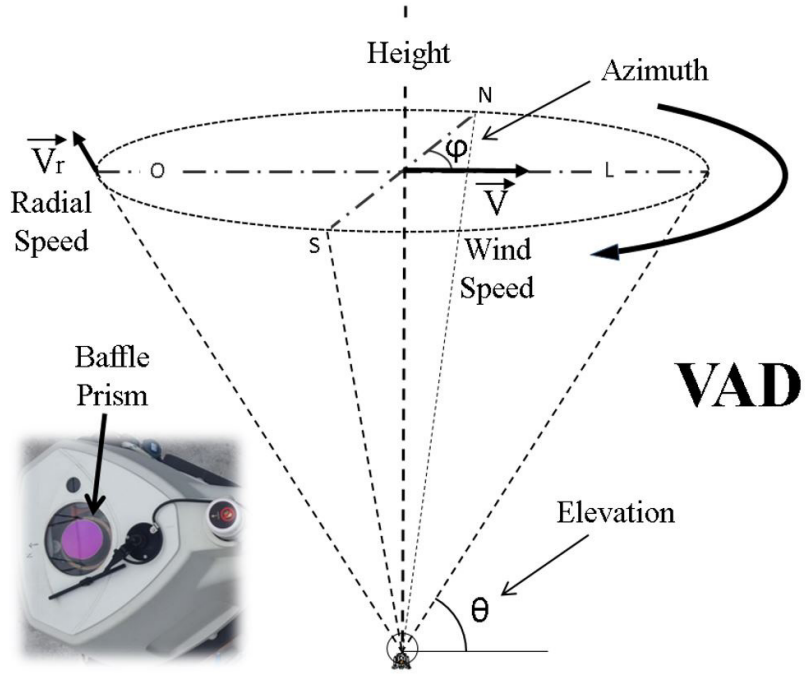

Figure 1. Graphical representation of the VAD (Velocity Azimuth Display) conical scanning. The deflector prism, responsible for the laser orientation is shown in the inserted figure. $\vec{V}_{r}$ refers to the radial wind speed along the beam, calculated by the Doppler effect of the return radiation scattered from aerosol particles. Over $50 \vec{V}_{r}$ measurements along the VAD are needed to compose the wind speed vector $\vec{V}$ at the cone's center. to buoy motion might introduce errors to the measurement of winds. There are two main approaches to circumvent this problem, improving the quality of observations (Howe, 2014). The first consists of mechanical stabilization platforms that minimize the effects of the buoy motion, keeping the LIDARs upright with respect to the horizon (Said et al., 2012; Tiana-Alsina et al., 2015). The second approach measures the LIDAR inclination and uses mathematical algorithms to convert the wind measurements to the earth-referenced frame (Edson et al., 1998; Yamaguchi \& Ishihara, 2015).

Mechanical stabilization systems, or Gimbals, can be further subdivided into two classes: passive mechanical and active electronic. Passive systems are cheaper, easier to manufacture and maintain. Gravity can be used as a restoration force to stabilize the system, allowing the compensation around two rotation axes (pitch and roll). Electronic active systems, on the other hand, monitor the instrument's inclinations and compensate for these motions with servomotors operating on two or three rotation axes (Arnold \& Maunder, 2014).

In this work, a passive mechanical system named "ESTABILIDAR" was designed and constructed for demonstration in a field campaign conducted in Furnas hydroelectric dam, Guapé, MG, Brazil. The stabilization system was designed with SolidWorks 2015 CAD software and prototyped to full-scale by the Mechanical Engineering Department of the Federal University of Santa Catarina (UFSC). The system is composed of three rectangular cuboid aluminum frames assembled together (Figure 2). Its external frame has $1.38 \mathrm{~m} \times 1.38 \mathrm{~m} \times 0.75 \mathrm{~m}$ and is fixed to the buoy. The external frame supports the intermediate structure with two axis-bearing assemblies. A similar coupling is used to mount the internal frame to the intermediate structure. This provides the system two axes of rotation, as shown in Figure 2. The labels (a) and (b) on this figure represent the sway of the intermediate frame around the y-axis, while the labels (c) and (d) represent the rotation of the internal frame around the $\mathrm{x}$-axis. Structural bars limit the maximum inclination of these frames to $25 \pm 1^{\circ}$. During operation, the LIDAR is positioned inside the internal frame, as shown in Figure 2. A bank of batteries is mounted inside the inner frame, helping to lower the center of gravity of the system. An inertial sensor mounted on the LIDAR recorded equipment oscillations not filtered by the stabilization system.

\section{Floating platform}

A floating platform, designed and manufactured by the Federal University of Itajubá (UFMG), was used in the measurement campaigns. The floating system consists of a $3 \mathrm{~m} \times 3 \mathrm{~m}$ barge supported by frames that connect $0.6 \mathrm{~m}$ diameter barrels, filled with polyethylene ${ }^{2}$ and covered by weathering resistance paint. The surface of the barge allows the mount of the ESTABILIDAR and other meteorological instruments as shown on Figure 3.

A 24-hour experiment was performed from September $20^{\text {th }}$, 2016 at 14:00 to September 21 ${ }^{\text {st }}, 2016$ at 14:00 in Furnas hydroelectric reservoir to evaluate the performance of the buoy-mounted LIDAR

\footnotetext{
Polyethylene has lower density than water and it was used as a safety measure in case of damage of the buoys hull.
} 


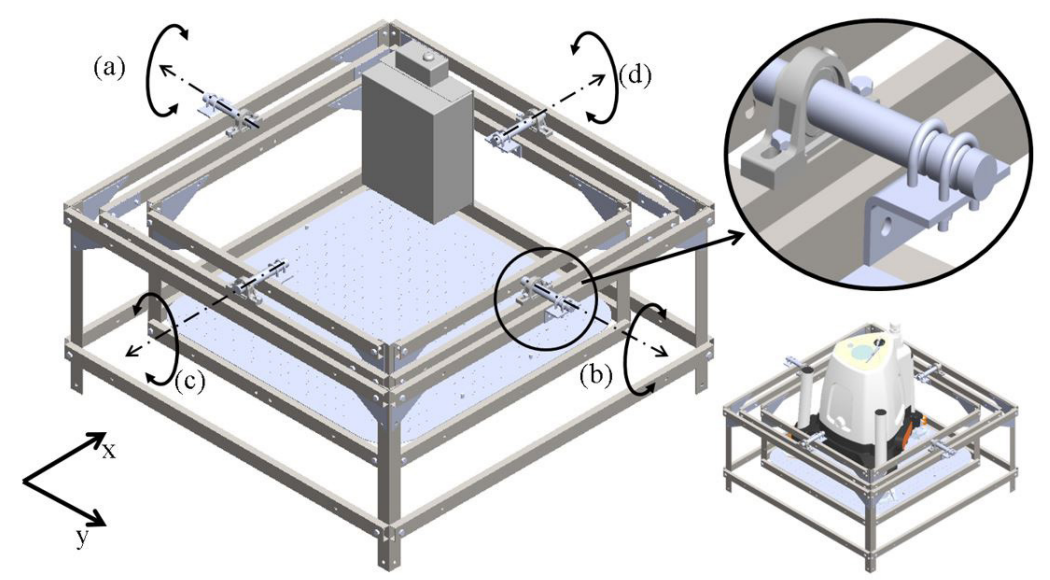

Figure 2. Project for the ESTABILIDAR motion compensation platform. This system is stabilized by gravitational force. The external frame is fixed to the buoy and the LIDAR and the battery system is mounted on the internal frame, which has two degrees of freedom for rotation around the $x$ and $y$ axes.

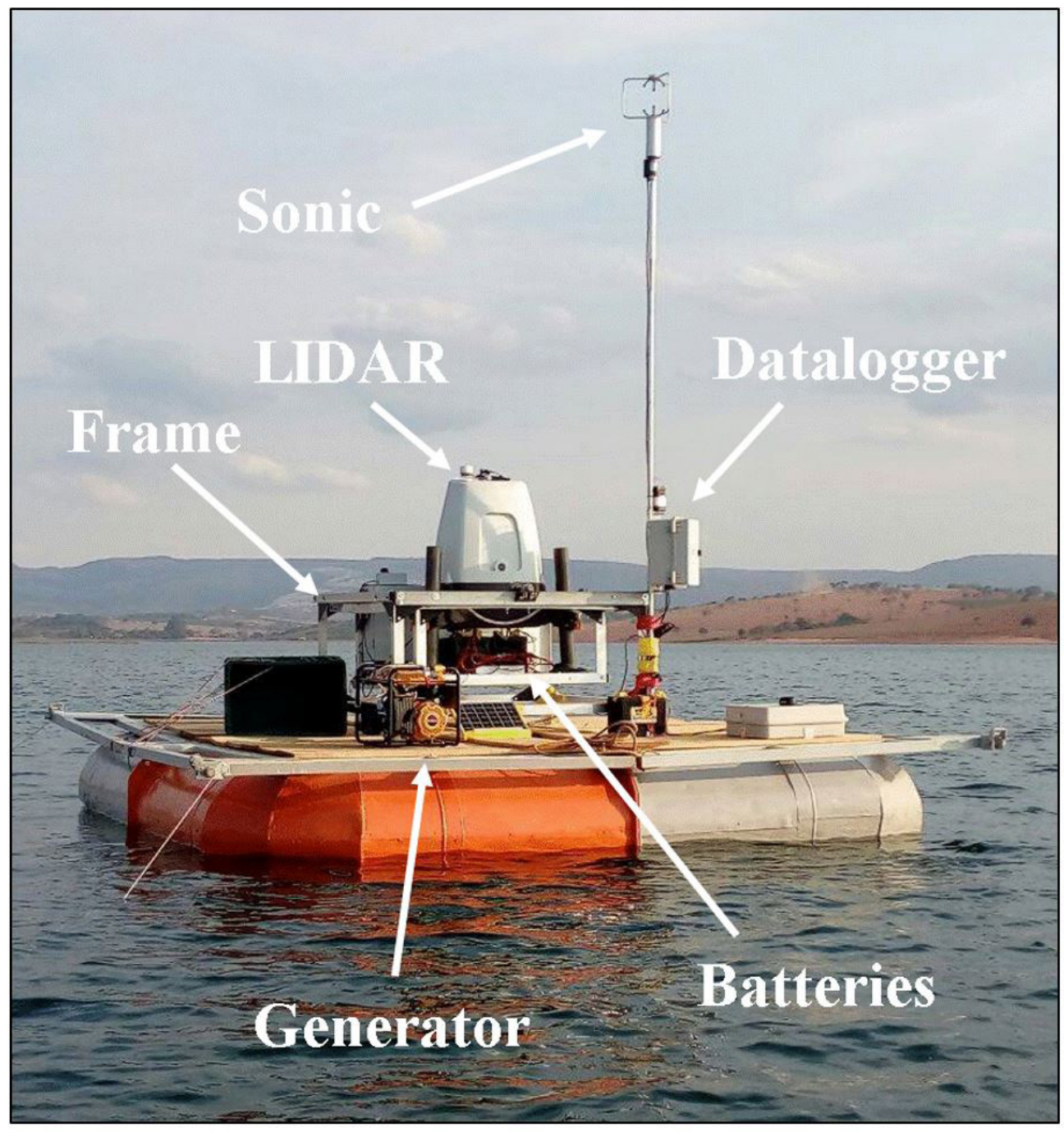

Figure 3. Floating LIDAR platform used in the Furnas hydroelectric reservoir experiment. The label "frame" indicates the ESTABILIDAR system, fixed to the buoy. The Zephir 300 LIDAR is installed on the inner frame, along with 450 Ah of $12 \mathrm{~V}$ batteries (nearly 40 hours of autonomous functioning) and an XSens MTI-G inertial sensor. A Young 81000 3D sonic anemometer is fixed to the buoy by a tall mast of $3.5 \mathrm{~m}$, along with temperature, pressure and humidity sensors. A Campbell CR1000 datalogger recorded the meteorological data. A gasoline generator supplied power for emergency recharge. 
system. Figure $4 \mathrm{a}$ indicates Furnas dam location in the state of Minas Gerais, Brazil. The hydroelectric dam is located $762 \mathrm{~m}$ above sea level and the highest topographical features are up to $100 \mathrm{~m}$ above the reservoir's water level. Figure $4 \mathrm{~b}$ illustrates the position of the mooring near the town of Guapé. The buoy was positioned $170 \mathrm{~m}$ from the coast in the northeasterly direction, $430 \mathrm{~m}$ in the westerly direction, and $330 \mathrm{~m}$ in the southeasterly direction at the latitude of $20^{\circ} 45^{\prime} 29^{\prime \prime} \mathrm{S}$ and longitude of $45^{\circ} 55^{\prime}$ $33^{\prime \prime} \mathrm{W}$. The floating platform was moored with four concrete sinkers tied to the edges of the buoy (Figure 4c), helping to maintain the buoy's orientation to the true north. Cables attached to the sinkers were adjusted under tension with ratchets. All sinkers are recoverable so that the system can be reinstalled in other regions.

An XSens MTi-G inertial sensor was assembled on the LIDAR to monitor inclinations at a frequency of $20 \mathrm{~Hz}$ (Figure 3). A GPS was used for the positioning of the equipment and time pairing. Three $12 \mathrm{~V} 150 \mathrm{Ah}$ batteries were wired in parallel and installed in the ESTABILIDAR inner frame, adding a load of $120 \mathrm{~kg}$.
This 450 Ah bank gives the LIDAR nearly 40 hours' autonomy. A gasoline-powered generator was available for emergency recharges.

\section{Algorithm correction}

An inertial sensor recorded residual pitch, roll and yaw angles motions of the LIDAR not compensated by the mechanical system. In order to mitigate the errors resulting from this motion, winds can be post-processed to convert the data from the instrument reference frame to the earth reference system. The process is typically carried out applying three sequential rotations of the speed vector $\overrightarrow{V^{\prime}}$ measured in the instrument reference system by means the following operation (Edson et al., 1998):

$$
V=Y^{*} P^{*} R * V^{\prime}
$$

where $\vec{V}=(u ; v ; w)$ is the wind speed vector referenced to the earth and $Y, P$, and $R$ are the matrices for yaw $(\gamma)$, pitch $(\alpha)$ and $\operatorname{roll}(\beta)$ :
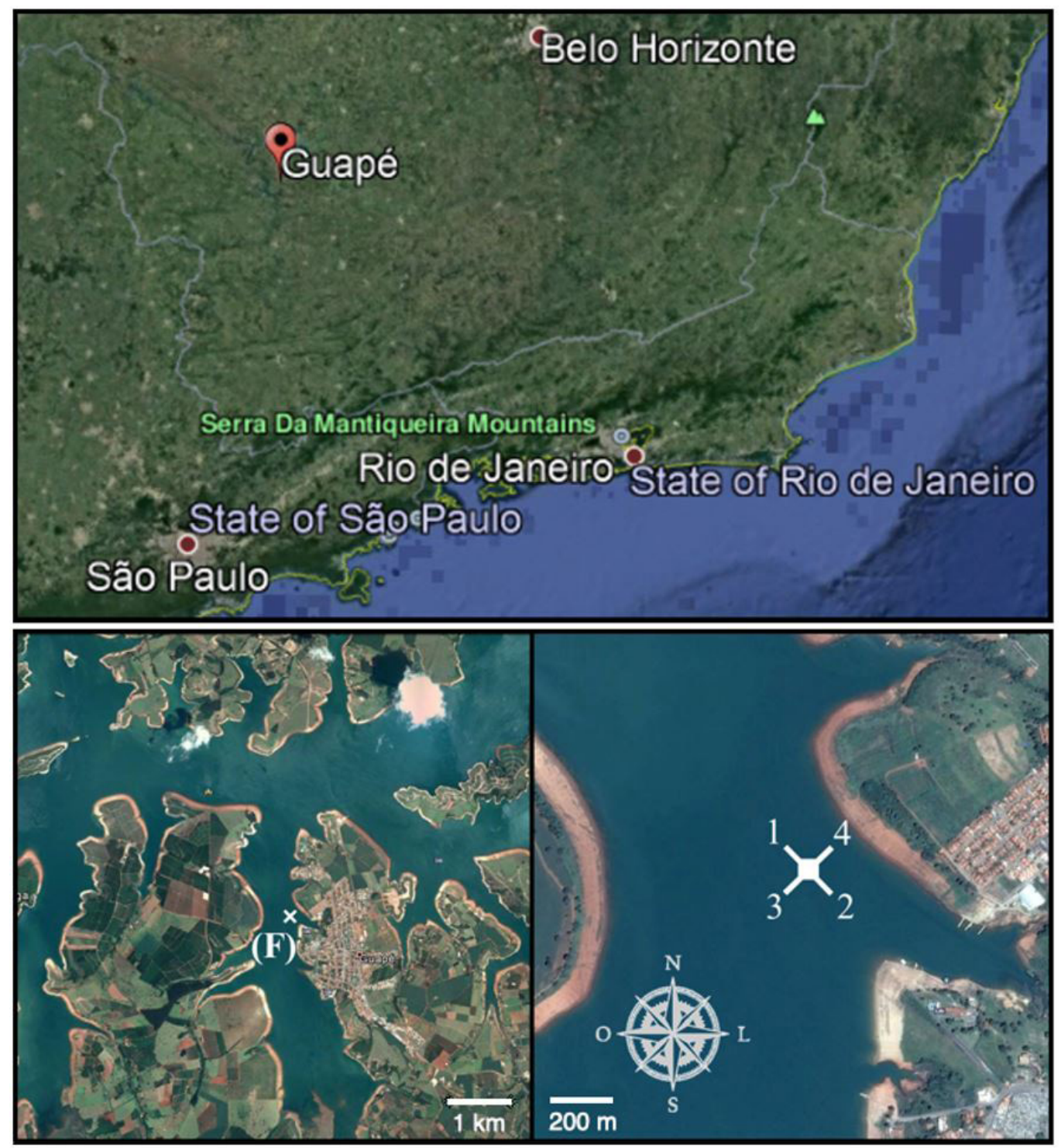

Figure 4. Map indicating the location of Guapé, MG, in the Brazilian southeast. (a) Furnas hydroelectric reservoir. Here "F" indicates the floating LIDAR platform; (b) Detailed map showing the LIDAR's location and the distribution of mooring anchors (numbers 1 to 4 ). 
$Y=\left(\begin{array}{ccc}\cos \gamma & -\sin \gamma & 0 \\ \sin \gamma & \cos \gamma & 0 \\ 0 & 0 & 1\end{array}\right)$

$P=\left(\begin{array}{ccc}\cos \alpha & 0 & \sin \alpha \\ 0 & 1 & 0 \\ -\sin \alpha & 0 & \cos \alpha\end{array}\right)$

$$
R=\left(\begin{array}{ccc}
1 & 1 & 0 \\
0 & \cos \beta & -\sin \beta \\
0 & \sin \beta & \cos \beta
\end{array}\right)
$$

$T=Y^{*} P^{*} R$ obtains the resulting rotation matrix. These equations consider positive yaw in the clockwise direction, in accordance with the work of Achtert et al. (2015). The X-Sens sensor mounted on the LIDAR samples in $20 \mathrm{~Hz}$. In comparison, the LIDAR takes nearly 1.6 seconds to compute the velocity at one level, including the time it takes to refocus the laser beam.

The system follows the right-hand rule and the sequential order of rotations is yaw, pitch, and roll, respectively. In the earth reference system, $x$ points to the East, $y$ to the North and $z$ is vertically aligned upwards. As in our experiment the buoy has no translational motion and also fixed alignment to the north, the yaw angle was set to $\gamma=0$.

\section{RESULTS}

\section{Meteorological conditions}

Figure 5 illustrates the meteorological conditions during the field campaign measured by the instrumented buoy. The first panel illustrates the wind speed magnitude as measured by the LIDAR at 10 and $200 \mathrm{~m}$ heights. The wind direction is illustrated on Figure 5b. Atmospheric pressure and temperature series are shown in Figure 5c.

In the beginning of the field experiment, winds were blowing from the northwest with moderate strength. Temperatures were around $30^{\circ} \mathrm{C}$ and atmospheric pressure was around $926 \mathrm{hPa}$. Synoptic fields from the ERA-interim (European Centre for Medium-Range Weather Forecasts, 2020) global atmospheric reanalysis (Dee et al., 2011) provided by the European Centre for Medium-Range Weather Forecasts (ECMWF) indicated the growing influence of an anticyclone, initially located in the coast of
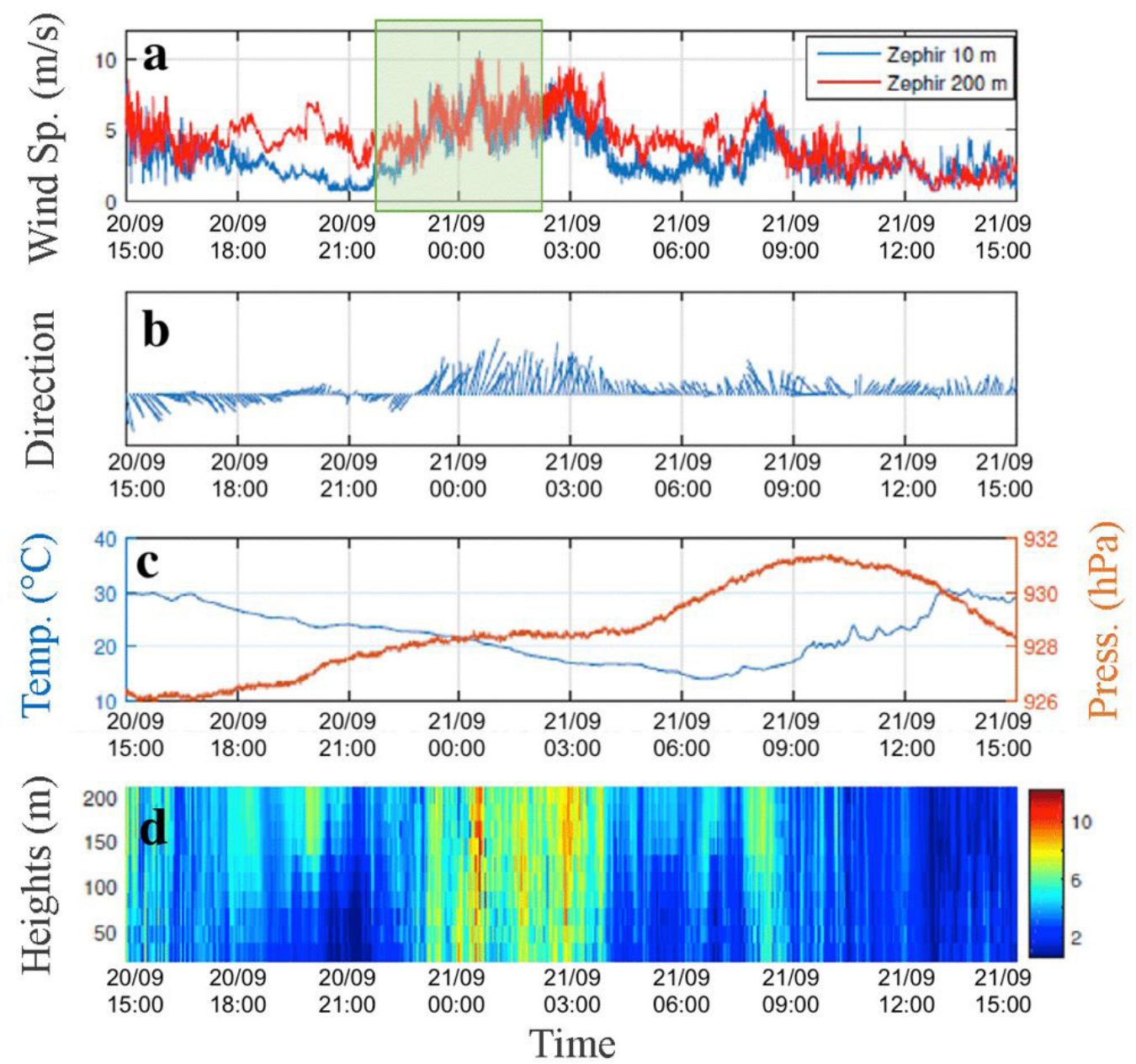

Figure 5. (a) LIDAR wind speed time series for 10 (blue line) and $200 \mathrm{~m}$ (red) heights; (b) Wind direction at $200 \mathrm{~m}$ height. Bars indicate the direction that wind is blowing in reference to the true north, represented by the vertical y-axis; (c) Temperature (blue) and pressure (red) time series; (d) Wind speed magnitude with height versus time. The colorbar indicates wind speed $\left(\mathrm{m} \mathrm{s}^{-1}\right)$. 
Uruguay (not shown). The high-pressure system moved northward along the southern coast of Brazil on September $21^{\text {st }}$ and the Furnas instrumented buoy recorded the corresponding changes in meteorological variables. There was an increase in atmospheric pressure to $931 \mathrm{hPa}$ and a reduction of air temperatures to $13{ }^{\circ} \mathrm{C}$ (Figure 5c). Winds also changed direction abruptly, starting to blow on September 20 $0^{\text {th }}$ 23:00 with a strong southern wind component (Figure 5b). During this event, weak vertical shear and speeds between 7 and $10 \mathrm{~m} \mathrm{~s}^{-1}$ were observed for nearly 6 hours. After this, winds resumed to speeds less than $5 \mathrm{~m} \mathrm{~s}^{-1}$ maintaining their direction.

Figure $5 \mathrm{~d}$ further presents the wind speed measured by the LIDAR for all the monitored heights. Colors represent the wind speed, with blue illustrating winds below $2 \mathrm{~m} \mathrm{~s}^{-1}$ and red winds above $10 \mathrm{~m} \mathrm{~s}^{-1}$. Therefore, strong (weak) wind shear can be identified by the occurrence of different (similar) colors with height. Figure $5 \mathrm{a}$ can also be used as a reference for vertical shear, following the speeds at 10 (blue) and $200 \mathrm{~m}$ height (red line). Weak (strong) wind shear occurs when the blue and red lines overlap (separate). The wind dataset as shown in Figure 5 was a result of the mechanical compensation instrument alone. In the following sections the LIDAR residual inclination is presented and used to convert its measurements to earth-referenced wind speeds.

\section{LIDAR residual inclinations}

Residual oscillations from the LIDAR were recorded for evaluation purposes. These correspond to oscillations that were not compensated by the mechanical stabilization system. Figure 6 presents a short record of the wind intensity measured by the LIDAR, along with the pitch and roll angles measured by the XSens sensor, installed in the ESTABILIDAR's inner frame.

The selected series correspond to the green shaded area of Figure $5 \mathrm{a}$ on September $20^{\text {th }}$, when winds started to change their direction to the southerly quadrant. Unfortunately XSens sensor did not record data from 14:50 to 21:50 on September 20 $0^{\text {th }}, 2016$.

Figure 6a illustrate periods of increasing and maximum wind speeds by the red and blue shaded areas respectively. The larger inclinations of pitch and roll coincide with the periods of highest wind speeds, between 00:00 and 00:30 (see blue boxes on Figure 6). The roll angle reached larger amplitudes $\left(10^{\circ}\right)$ than the pitch $\left(5^{\circ}\right)$, as the prevailing direction of winds and waves acted perpendicularly to the roll axis. Winds were also coincident with the reservoir's south fetch, which favored the development of gravity waves that gradually increased their height and periods before reaching the buoy position (Figure 4). Considering the buoy distance from the coast varying from $1400 \mathrm{~m}$ to $3400 \mathrm{~m}$, southerly winds of $7 \mathrm{~m} \mathrm{~s}^{-1}$ and fetch-limited surface gravity waves, this corresponds
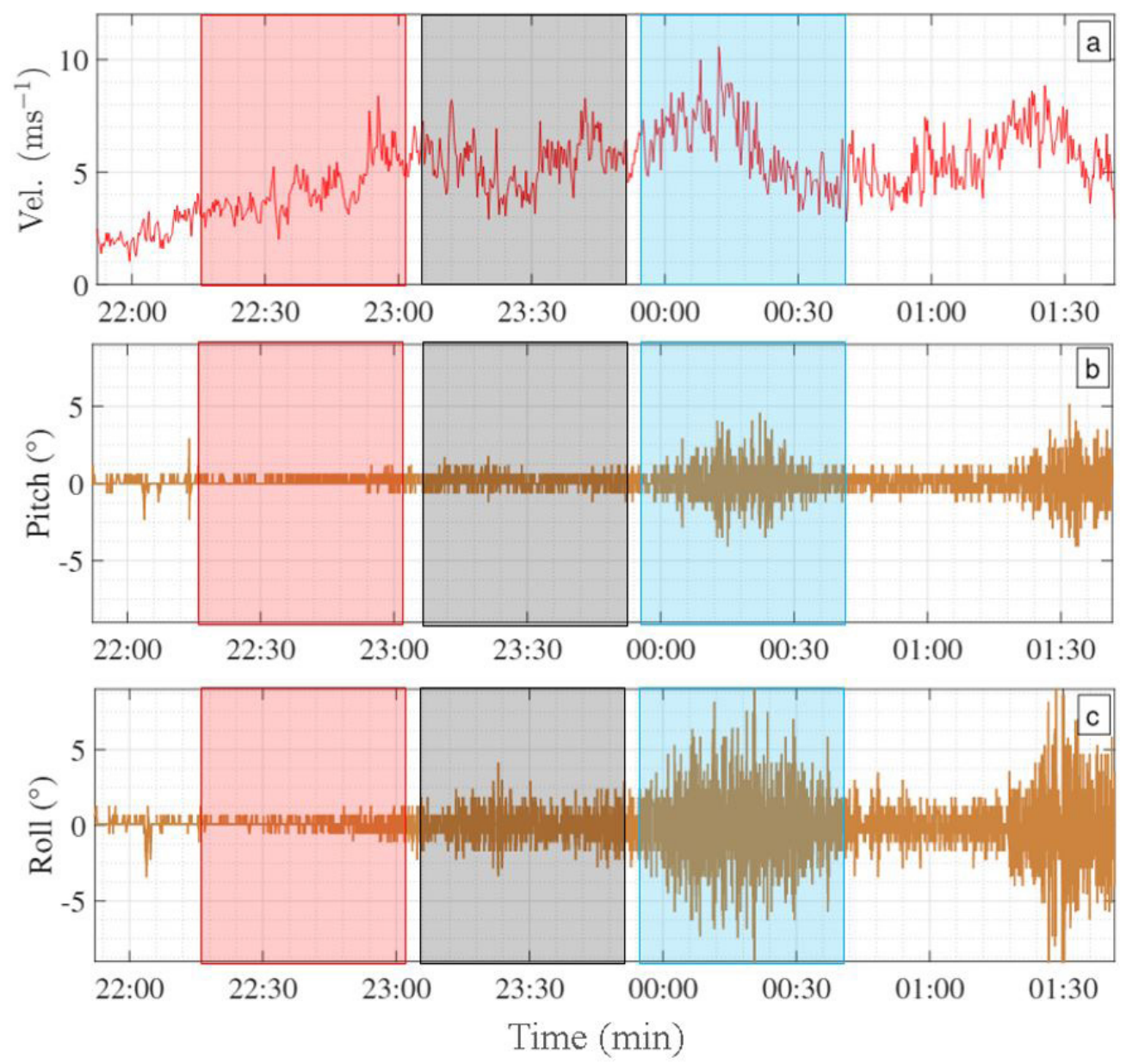

Figure 6. (a) Zephir LIDAR wind speed at $10 \mathrm{~m}$ height; (b) Time series of pitch a, (degrees); (c) Time series of the roll $\beta$ angle (degrees). These series refer to nearly 3 hours of records made on $21^{\text {st }}$ September 2015, local time (see Figure $5 \mathrm{a}$ for reference). 
to expected significant wave heights between $0.13 \leq H_{s} \leq 0.20 \mathrm{~m}$ and peak periods between $1.00 \leq T_{p} \leq 1.36 \mathrm{~s}$ (U. S. Army Corps of Engineers, 2002).

\section{Conversion of winds to the earth reference}

The residual inclinations measured by the inertial sensor turns possible the correction of winds for motions not attenuated by the mechanical system. Using the pitch $\alpha$ and roll $\beta$ angles recorded by XSens sensor, one can compute the matrices from Equations 2, 3 and 4 in order to convert the instrument referenced wind vector $\vec{V}^{\prime}$ to the earth-referenced wind $\vec{V}$ applying Equation 1 . As the pitch and roll angles are measured at higher frequency $(20 \mathrm{~Hz})$ compared to the LIDAR data $(0.06 \mathrm{~Hz})$ the later is assumed to be constant during the matrix rotation.

Figure 7 illustrates a short record of the LIDAR wind time series for the height of $100 \mathrm{~m}$ before and after this correction. The blue line represents the wind horizontal magnitude before the conversion. Conversely, the red line represents the winds after the correction. The "broken" pattern of the blue curve evidences the time resolution of the LIDAR measurements. The LIDAR takes nearly 1 second to complete the scan at any level, but around 15 seconds to repeat that scan in a specific level. The wavy pattern identified on the red curve corresponds to the higher frequency correction computed from pitch and roll angles recorded at higher frequency ( $\mathrm{f}=20 \mathrm{~Hz}$, or $\Delta \mathrm{t}=0.05$ seconds).

Comparing both curves it is remarkable that differences are less than $0.1 \mathrm{~m} \mathrm{~s}^{-1}$. The horizontal speed is sometimes underestimated and at other times overestimated, due to the swaying of the equipment (Nassif, 2017).

Table 2 further illustrates the minimum, maximum and the standard deviations for the time series of pitch, roll and the velocity errors at the levels of 10,100 and $200 \mathrm{~m}$ height. Here the velocity errors are estimated as $\Delta \mathrm{V}=\mathrm{V}_{\mathrm{h}}{ }^{\prime}-\mathrm{V}_{\mathrm{h}}$, where $\mathrm{V}_{\mathrm{h}}$ ' and $\mathrm{V}_{\mathrm{h}}$ refer to the horizontal wind speed components on the instrument and earth reference frames respectively. Higher inclination angles imply larger deviations for the corrected speed. Maximum and minimum pitch angles were around $\pm 6^{\circ}$ and roll angles around $\pm 11^{\circ}$. Average pitch and roll angles were below $1^{\circ}$ with a standard deviation of less than $1.6^{\circ}$, an indication of a reasonable performance of the stabilization system. The maximum and minimum wind speed differences $\Delta \mathrm{V}$ remained below $\pm 0.4 \mathrm{~m} \mathrm{~s}^{-1}$ with a standard deviation below $0.02 \mathrm{~m} \mathrm{~s}^{-1}$ for all heights. Average values for $\Delta \mathrm{V}$ were smaller than $\pm 0.01 \mathrm{~m}$ $\mathrm{s}^{-1}$ demonstrating that the LIDAR residual errors are negligible for buoy inclinations of up to $10^{\circ}$.

Other studies have assessed similar velocity errors. Yamaguchi \& Ishihara (2015) found negligible deviations for angles up to $6^{\circ}$. Inclinations of $5^{\circ}$ were observed by Mangat et al. (2014) with a velocity error below $0.3 \%$. Pitter \& Woodward (2015) suggest that whenever 10-minute averages are calculated, there is no need to apply any motion compensation algorithm. As the buoy's motions are periodic and nearly symmetrical, errors due to waves tend to be compensated for the 10 min averages. LIDAR winds presented on Figure 5 have great accuracy despite the instrument's residual motions.

\section{Inclination effects on the spatial scanning}

The VAD (Velocity Azimuth Display) scanning made by a continuous emission LIDAR has some of its characteristics affected when its reference axis is tilted by the buoy motion. Figure 8 illustrates the some basic conical scanning parameters and the effects of the LIDAR inclination.

Table 2. Minimum, maximum, average (Avg) and standard deviations (SD) for pitch, roll and estimated velocity errors $(\Delta \mathrm{V})$.

\begin{tabular}{|c|c|c|c|c|c|c|c|c|c|}
\hline \multirow{2}{*}{ Height } & \multicolumn{3}{|c|}{ PITCH $\left(^{\circ}\right)$} & \multicolumn{3}{|c|}{ ROLL $\left(^{\circ}\right)$} & \multicolumn{3}{|c|}{$\Delta \mathrm{V}\left(\mathrm{m} \mathrm{s}^{-1}\right)$} \\
\hline & $10 \mathrm{~m}$ & $100 \mathrm{~m}$ & $200 \mathrm{~m}$ & $10 \mathrm{~m}$ & $100 \mathrm{~m}$ & $200 \mathrm{~m}$ & $10 \mathrm{~m}$ & $100 \mathrm{~m}$ & $200 \mathrm{~m}$ \\
\hline Min & -4.01 & -5.73 & -4.58 & -11.38 & -11.95 & -11.38 & -0.07 & -0.12 & -0.10 \\
\hline Max & 5.15 & 6.30 & 5.16 & 9.82 & 11.54 & 10.96 & 0.21 & 0.37 & 0.15 \\
\hline $\mathrm{SD}$ & 0.73 & 0.75 & 0.70 & 1.61 & 1.62 & 1.62 & 0.01 & 0.02 & 0.01 \\
\hline Avg & 0.43 & 0.43 & 0.40 & 1.00 & 0.98 & 0.97 & $<0.01$ & $<0.01$ & $<0.01$ \\
\hline
\end{tabular}

Here $\Delta \mathrm{V}=\mathrm{V}_{\mathrm{h}}{ }_{\mathrm{h}}-\mathrm{V}_{\mathrm{h}}$, where $\mathrm{V}_{\mathrm{h}}$, and $\mathrm{V}_{\mathrm{h}}$ refer to the horizontal wind speed components on the instrument and earth reference frames respectively. Average values for $\Delta \mathrm{V}$ were smaller than $\pm 0.01 \mathrm{~m} \mathrm{~s}^{-1}$.

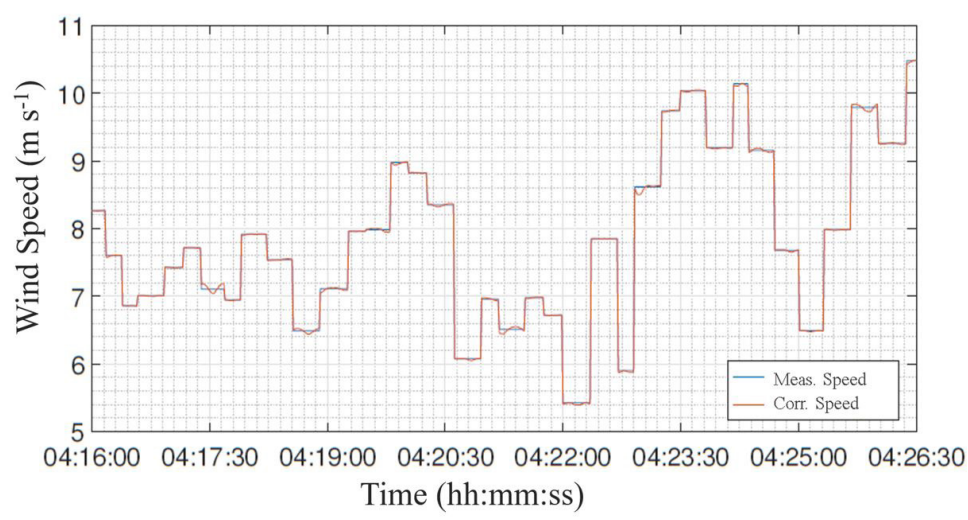

Figure 7. Wind's horizontal speed at $100 \mathrm{~m}$. The blue line refers to the wind's horizontal speed (Vh') as measured by the instrument (LIDAR) reference system. The red line corresponds to the wind's horizontal velocity described in the earth reference frame (Vh). 
Let us first comment on the operation of the equipment on normal conditions over a stable and horizontal surface. The laser path forms a cone with a $30^{\circ}$ angle to the vertical axis. The beam's focus has constant height, but the control volume varies from $\pm 0.1 \mathrm{~m}$ at the height of $10 \mathrm{~m}$ to $\pm 6 \mathrm{~m}$ at $100 \mathrm{~m}$ height. The wind speed vector $\mathrm{V}_{\text {obs }}$ is supplied for the center of the cone at the height $z$. The height $z$ is also referred as the target height, when the equipment is vertically aligned as shown in Figure 8a.

When tilted by the buoy's motion, the cone is inclined by an angle $\delta$ to the vertical axis, as shown in Figure $8 \mathrm{~b}$. This inclination modifies the center of wind measurement to the height $z^{\prime}$. The laser path also covers a layer of thickness $\Delta z$, defined as the difference of the heights $z_{\max }$ and $z_{\min }$. The beam's length is $L=z / \cos \left(30^{\circ}\right)$. The height $z^{\prime}$ is computed by:

$z^{\prime}=z \cos (\delta)$

The maximum height scanned by the cone is:

$z_{\max }=\frac{z \cos (30-\delta)}{\cos \left(30^{\circ}\right)}$

and the minimum height:

$z_{\text {min }}=\frac{z \cos (30+\delta)}{\cos \left(30^{\circ}\right)}$
The overall inclination, caused by the combined pitch $(\alpha)$ and roll $(\beta)$ angles is computed by:

$\delta=\cos ^{-1}\left(\cos \alpha^{*} \cos \beta\right)$

The height $z_{\max }$ increases with growing inclination angle $\delta$, reaching $z_{\max }=L$ for $\delta=30^{\circ}$. Thereafter, $z_{\max }$ decreases for $\delta>30^{\circ}$. The heights $z^{\prime}$ and $z_{\min }$ decrease for increasing values of $\delta$. Table 3 shows how $z^{\prime}, z_{\min }, z_{\max }$, and $\Delta z=z_{\max }-z_{\min }$ vary with $\delta$ for the target heights of $z=10,100$ and $200 \mathrm{~m}$. The greater the target height $z$ and the angle $\delta$ are, the larger is the $\Delta z$ layer thickness. As an example, for $\delta=15^{\circ}$ at $z=100 \mathrm{~m}$, the central point of measurement $z^{\prime}$ is only $3.4 \mathrm{~m}$ below the target height, but the scanning thickness samples a control volume thicker than $\Delta z=29.9 \mathrm{~m}$.

This suggest that minimizing the magnitude of the inclination angle might be a crucial for proper vertical sampling, as the 50 measurements performed along the VAD will sample winds at different layers for large inclinations. Reducing the inclination to $10^{\circ}$, reduces $\Delta z$ to $20 \mathrm{~m}$ and for $\delta=5^{\circ}, \Delta z=10 \mathrm{~m}$ at $\mathrm{z}=100 \mathrm{~m}$ (Table 3).

The effects of the buoy's motion on these parameters are further illustrated in Figure 9. The graph illustrates the temporal variability of $z^{\prime}, z_{\min }$ and $z_{\max }$ for the heights of $z=10$, 40, 100 and $200 \mathrm{~m}$ due to residual LIDAR motions. The record

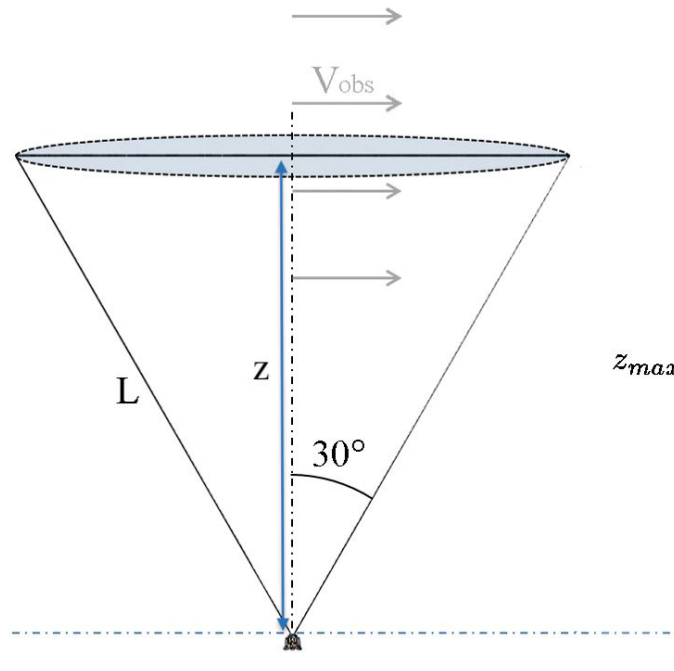

Vertical LiDAR

(a)

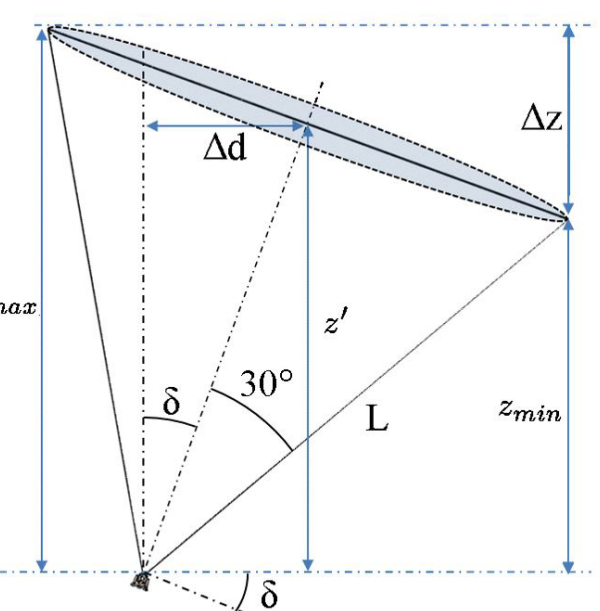

Inclined LiDAR

(b)

Figure 8. (a) Graphical illustration of the LIDAR conical VAD with the measurement height $z$. The height $z$ refers to the distance of the LIDAR top to the center of a ring formed by the laser conical scan. This is also referred as the target height, when the LIDAR is vertically aligned; (b) Effect of inclination angle $\delta$ on the LIDAR conical scan heights $\left(z^{\prime}, z_{\min }, z_{\max }\right)$ and thickness $(\Delta z)$ of the control volume.

Table 3. Effect of the LIDAR inclination on different parameters of the VAD conical scanning, as function of the target height $z$. See Figure 8 for parameters definition.

\begin{tabular}{|c|c|c|c|c|c|c|c|c|c|}
\hline \multirow{2}{*}{$\begin{array}{l}z \\
\delta\end{array}$} & \multicolumn{3}{|c|}{$10 \mathrm{~m}$} & \multicolumn{3}{|c|}{$100 \mathrm{~m}$} & \multicolumn{3}{|c|}{$200 \mathrm{~m}$} \\
\hline & $5^{\circ}$ & $10^{\circ}$ & $15^{\circ}$ & $5^{\circ}$ & $10^{\circ}$ & $15^{\circ}$ & $5^{\circ}$ & $10^{\circ}$ & $15^{\circ}$ \\
\hline$z^{\prime}$ & 9.9 & 9.8 & 9.6 & 99.6 & 98.5 & 96.6 & 199.2 & 197.0 & 193.2 \\
\hline$z_{\min }$ & 9.4 & 8.8 & 8.2 & 94.6 & 88.4 & 81.6 & 189.2 & 176.9 & 163.3 \\
\hline$z_{\max }$ & 10.5 & 10.8 & 11.1 & 104.6 & 108.5 & 111.5 & 209.3 & 217.0 & 223.1 \\
\hline$\Delta z$ & 1.0 & 2.0 & 3.0 & 10.1 & 20.0 & 29.9 & 20.1 & 40.1 & 59.8 \\
\hline
\end{tabular}


shows 1200 samples at $20 \mathrm{~Hz}$, which represents a 1 min record. A typical logarithmic wind profile is overlaid for reference (see the gray dashed line in Figure 9). The curve helps to indicate how the LIDAR's heights of measurements vary in time, in comparison to a typical wind profile. The movement affects the VAD cone sampling. The thickness $\Delta z$ is quite small for 10 and $40 \mathrm{~m}$ but attains larger amplitudes for 100 and $200 \mathrm{~m}$ heights. In rare situations $z_{\min }$ and $z_{\max }$ exceed the limits defined by the control volume

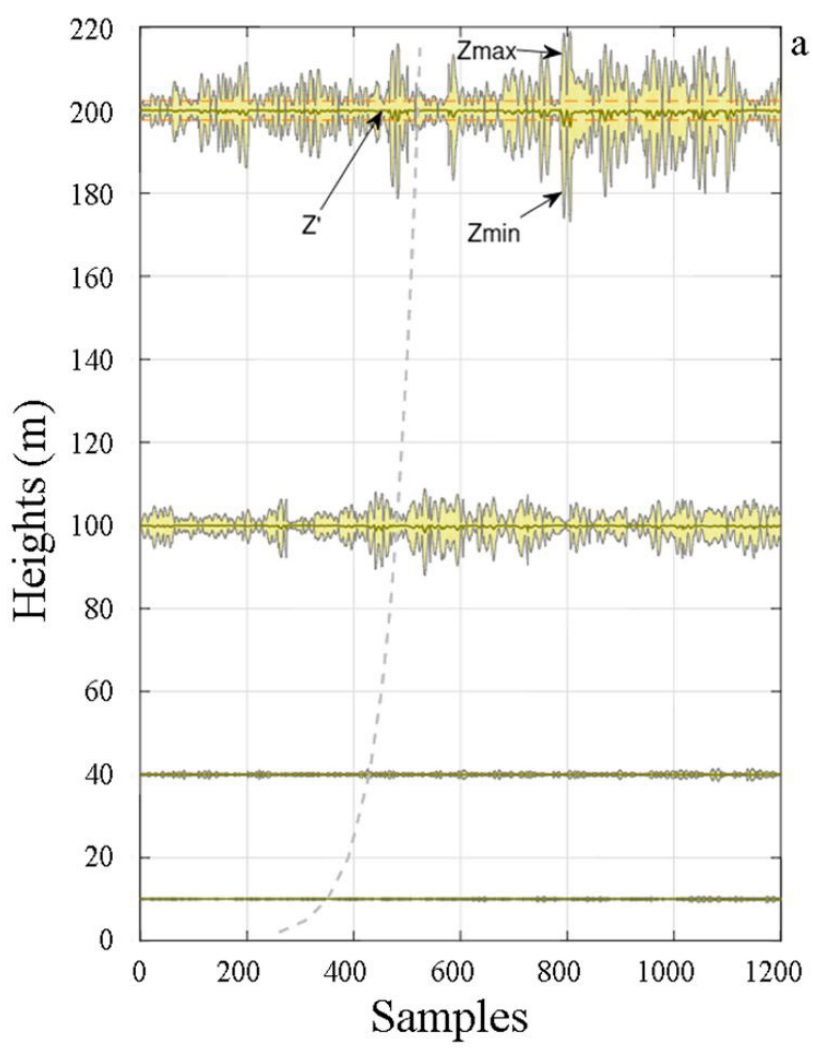

Figure 9. (a) LIDAR observations' height variability due to the residual buoy motion. Here labels $z^{\prime}, z_{\min }$, and $z_{\max }$ respectively, represent the average, minimum and maximum VAD cone heights due to instrument inclination (see Figure 8). These parameters are computed for $z=10,40,100$ and $200 \mathrm{~m}$ target heights. A gray dashed line illustrates a typical logarithmic wind profile. A red dashed line represents average values of $z_{\min }$ and $z_{\max }$ for $200 \mathrm{~m}$. for $z=100 \mathrm{~m}$, which is close to $\pm 6 \mathrm{~m}$ (total amplitude of $12 \mathrm{~m}$ ). Velocity errors associated with larger control volumes will tend to be small however, as winds are less sheared at higher levels.

Figure 10 confirms this hypothesis plotting the LIDAR wind speed standard deviation as a function of height, for regimes of low, medium and high inclinations. Such periods correspond to the situations previously described in Figure 6. Results show that larger oscillations have higher standard deviations for lower levels, below $80 \mathrm{~m}$. As the height is increased, the wind speed's standard deviation is nearly the same and around $1 \mathrm{~m} \mathrm{~s}^{-1}$, despite the amplitude of the inclinations. This analysis demonstrates that Zephir 300 presents the best scanning capacity above $80 \mathrm{~m}$, where the standard deviation remains around $1 \mathrm{~m} \mathrm{~s}^{-1}$.

\section{Height correction for large inclination angles}

Figure 11 further explores the impact of large LIDAR inclinations on the profile representation. An idealized profile of form $v(z)=v_{r} \ln \left(z / z_{0}\right) / \ln \left(z_{r} / z_{0}\right)$ is again shown as a black line. Here $\mathrm{v}_{\mathrm{r}}$ is the reference velocity $\left(\mathrm{m} \mathrm{s}^{-1}\right), \mathrm{z}$ is the target height $(\mathrm{m})$ and $z_{0}=0.2 \mathrm{~mm}$ is the typical aerodynamic roughness length for aquatic environments. This curve is used as a reference profile.

Next, the effect of different inclinations $\delta$ upon the VAD sampling are simulated, taking into account the heights $z_{\min }$ and $z_{\max }$ covered by the laser path. That is, each velocity estimate is carried out sampling 50 speeds of the reference profile between $z_{\min }$ and $z_{\max }$ (Figure 8). The average speed is then plotted as different symbols for different $\delta$ inclination angles. As shown in Figure 11, for $\delta=0^{\circ}$, points lay exactly over the wind log-profile.

As the LIDAR inclination $\delta$ is increased, the laser cone tends to sample winds at lower heights z' (Figure 8b). Therefore, the average performed by the VAD intercepts winds in different layers. As this average is mistakenly reported to a target height $z$, results can be misinterpreted as the occurrence of lower wind speeds at higher levels. This effect is shown by the different symbols of Figure 11, which illustrate that weaker wind profiles will be reported for growing inclination angles.

A way to circumvent this error is simply the correction for the true observation height $z^{\prime}$ (Equation 5). The result of this practice is illustrated by the black triangles in the same graph, which more closely follow the reference log wind profile. As seen

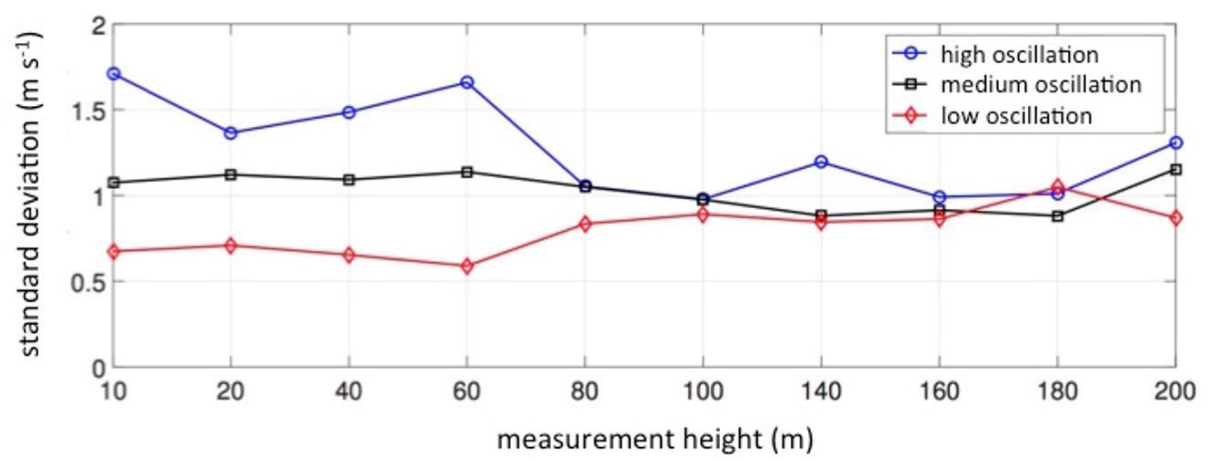

Figure 10. Wind speed standard deviation as function of the LIDAR measurement height $z$, for different periods of observation. Line colors identify the different regimes of oscillation from 01:00 am to 03:30 am, as shown in Figure 6. 


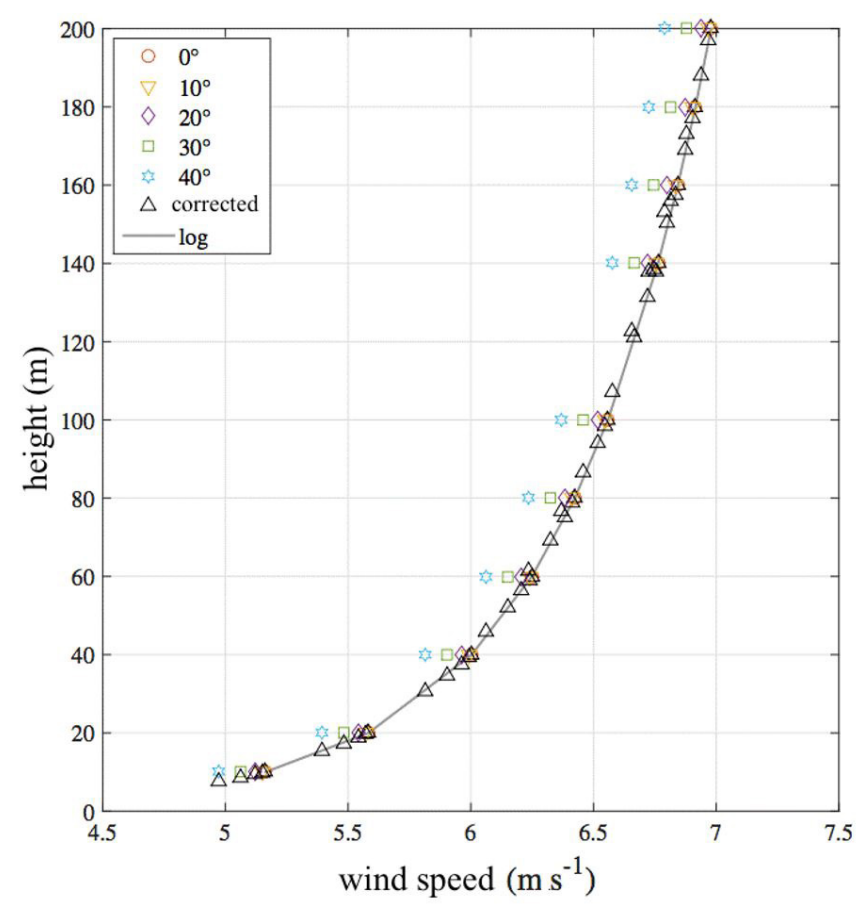

Figure 11. Wind profile averages for different LIDAR inclinations, before and after applying the height correction. A continuous black line illustrates the logarithmic profile used for reference. Colored symbols indicate average velocities computed for the target $z$ heights of 10, 20, 40, 60, 80, 100, 140, 160, 180 and $200 \mathrm{~m}$. Black triangles present the same averaged data, after correction for the scan height $z^{\prime}$ due to the LIDAR's inclination (see Equation 5). As shown, higher inclination angles can lead to underestimation of the wind profile, as the conical scan register winds at lower levels, but report these at higher (target) heights.

for the height of $100 \mathrm{~m}$, the error for $40^{\circ}$ inclination is reduced from $0.25 \mathrm{~m} \mathrm{~s}^{-1}$ (blue star) to nearly $0.02 \mathrm{~m} \mathrm{~s}^{-1}$ after correction (see black triangles).

The correction for the true measurement height $z^{\prime}$ avoids the underestimation of the true wind profile. The simulation suggest, however, that small errors should be expected even after $z^{\prime}$ correction. This is due to the larger thickness of the atmosphere sampled by the VAD, shown as the black triangles' differences from the true wind profile (Figure 11).

\section{SUMMARY AND CONCLUSIONS}

This study describes the development of a buoy-mounted LIDAR for assessing the wind resources of Brazil's sheltered aquatic systems. A mechanical stabilization system and analytical methods are used for the compensation of the motion of the LIDAR. A field experiment was conducted on the Furnas hydroelectric reservoir to test the mechanical system, measure the LIDAR's residual motions and assess the characteristics of the wind profile. This was an experimental buoy-mounted system and the main point was to test and report the errors associated to the buoy's motion.

Field observations demonstrated that the mechanical stabilization system is an affordable solution to filter lower- frequency movements due to waves, but it was not capable of damping higher-frequency oscillations. Tiana-Alsina et al. (2015) have shown a stabilization system that demonstrated a similar response and worked mainly for lower-frequency oscillations ( $\mathrm{f}=1 / 12 \mathrm{~Hz}$ or $\Delta \mathrm{t}=12$ seconds).

Our analysis demonstrates that LIDAR errors due to small amplitude waves (inclinations of up to $10^{\circ}$ ) tend to be negligible. The use of an inertial sensor allows the post-processing of the LIDAR data with (i) conversion of winds from the instrument- to the earth-referenced frame and (ii) corrections to the sampling height z'. Despite the buoy's motion, it is possible to obtain high quality measurements for averaged LIDAR data, which demonstrates higher reliability above $80 \mathrm{~m}$ height. The LIDAR conical scanning features can be influenced by large system inclinations, but these can be corrected with inertial sensor measurements to avoid misinterpretations of the wind profile.

The mechanical stabilization system could be improved with a device for damping of high-frequency oscillations $(>1 \mathrm{~Hz}$ ) or the inclusion of servomotors. Added protection is needed for the electrical system. The integration of solar panels into the battery bank will make this system suitable for long term monitoring of Brazilian reservoirs.

Hydroelectric environments have complex neighbouring relief, and display large spatial variability of winds (Assireu et al., 2011, 2013). In that respect, the buoy-mounted LIDAR will be particularly useful for the survey of different geographical regions and identification of the most attractive regions for wind power development. The buoy-mounted LIDAR system described in this work still needs to be adapted for use in the open ocean. That will require autonomous communication systems, protection against marine corrosion and a mooring system adapted for deeper waters and larger waves.

\section{ACKNOWLEDGEMENTS}

This work was supported by the Project MOVLIDAR by CNPq (406801/2013-4). FMP acknowledges Project MOVLIDAR and INEOF/INCT from CNPq (406801/2013-4, 311930/2016-6 and 465672/2014-0). ATA acknowledge FAPEMIG (APQ 1575/14) and CNPq (309315/2015-8). The original article was improved through the helpful remarks of the anonymous reviewers.

\section{REFERENCES}

Achtert, P., Brooks, I. M., Brooks, B. J., Moat, B. I., Prytherch, J., Persson, P. O. G., \& Tjernström, M. (2015). Measurement of wind profiles by motion-stabilised ship-borne doppler LIDAR. Atmospheric Measurement Techniques, 8(11), 4993-5007. http://dx.doi. org/10.5194/amt-8-4993-2015.

Arnold, R. N., \& Maunder, L. (2014). Gyrodynamics and its engineering applications. New York: Academic Press.

Assireu, A. T., Pellegrini, C., \& Pimenta, F. M. (2013). Intensificação do vento devido a influências do relevo: evidências a partir de modelos numéricos e medidas in situ. Ciência e Natura, 0(0), 76-78. http://dx.doi.org/10.5902/2179460X11550. 
Assireu, A. T., Pimenta, F. M., \& Souza, V. (2011). Assessment of the wind power potential of hydroelectric reservoir. In E. Alcântara (Ed.), Energy resources: development, distribution, and exploitation (1st ed., pp. 1-30). New York: Nova Science Publishers.

Cariou, J.-P. (2013). Pulsed LIDARS. In DTU Wind Energy, Remote sensing for wind energy (DTU Wind Energy-E-Report-0029(EN), pp. 104-121). Roskilde, Denmark: DTU Wind Energy.

Dee, D. P., Uppala, S. M., Simmons, A. J., Berrisford, P., Poli, P., Kobayashi, S., Andrae, U., Balmaseda, M. A., Balsamo, G., Bauer, P., Bechtold, P., Beljaars, A. C. M., Van de Berg, L., Bidlot, J., Bormann, N., Delsol, C., Dragani, R., Fuentes, M., Geer, A. J., Haimberger, L., Healy, S. B., Hersbach, H., Hólm, E. V., Isaksen, L., Kållberg, P., Köhler, M., Matricardi, M., McNally, A. P., Monge-Sanz, B. M., Morcrette, J.-J., Park, B.-K., Peubey, C., de Rosnay, P., Tavolato, C., Thépaut, J.-N., \& Vitart, F. (2011). The ERA-INTERIM reanalysis: configuration and performance of the data assimilation system. Quarterly Journal of the Royal Meteorological Society, 137(656), 553-597. http://dx.doi.org/10.1002/qj.828.

Edson, J. B., Hinton, A. A., Prada, K. E., Hare, J. E., \& Fairall, C. W. (1998). Direct covariance flux estimates from mobile platforms at sea. Journal of Atmospheric and Oceanic Technology, 15(2), 547-562. http://dx.doi.org/10.1175/1520-0426(1998)015<0547:DCFE $\mathrm{FM}>2.0 . \mathrm{CO} ; 2$.

Empresa de Pesquisa Energética - EPE. (2020). Roadmap É́lica Offshore Brasil: technical report. Brasília. Retrieved in 2020, May 11, from http://www.epe.gov.br

European Centre for Medium-Range Weather Forecasts - ECMWF. (2020). ER A-Interim. Retrieved in 2020, May 11, from ttps://www. ecmwf.int/en/forecasts/datasets/reanalysis-datasets/era-interim

Garvine, R. W., \& Kempton, W. (2008). Assessing the wind field over the continental shelf as a resource for electric power. Journal of Marine Research, 66(6), 751-773. http://dx.doi. org/10.1357/002224008788064540.

Gottschall, J., Wolken-Möhlmann, G., Viergutz, T., \& Lange, B. (2014). Results and conclusions of a floating-LIDAR offshore test. Energy Procedia, 53, 156-161. http://dx.doi.org/10.1016/j. egypro.2014.07.224.

Hasager, C. B. (2014). Offshore winds mapped from satellite remote sensing. WIREs Energy \& Environment, 3(6), 594-603. http://dx.doi.org/10.1002/wene.123.

Hasager, C. B., Stein, D., Courtney, M., Peña Diaz, A., Mikkelsen, T., Stickland, M., \& Oldroyd, A. (2013). Hub height ocean winds over the North Sea observed by the NORSEIWInD LIDAR array: measuring techniques, quality control and data management. Remote Sensing, 5(9), 4280-4303. http://dx.doi.org/10.3390/rs5094280.

Howe, G. (2014). Developing a buoy-based offshore wind resource assessment system. Sea Technology Magazine, 55(2), 41-46.
Hsuan, C.-Y., Tasi, Y.-S., Ke, J.-H., Prahmana, R. A., Chen, K.-J., \& Lin, T.-H. (2014). Validation and measurements of floating LIDAR for nearshore wind resource assessment application. Energy Procedia, 61,1699-1702. http://dx.doi.org/10.1016/j.egypro.2014.12.195.

Li, J., \& Yu, X. B. (2017). LIDAR technology for wind energy potential assessment: demonstration and validation at a site around lake Erie. Energy Conversion and Management, 144, 252-261. http:/ / dx.doi.org/10.1016/j.enconman.2017.04.061.

Mangat, M., Des Roziers, E. B., Medley, J., Pitter, M., Barker, W., \& Harris, M. (2014). The impact of tilt and inflow angle on ground based LIDAR wind measurements. In EWEA 2014 Annual Event Proceedings. Brussels: EWEA.

Mathisen, J.-P. (2013). Measurement of wind profile with a buoy mounted LIDAR. Energy Procedia, 30(12), 1-10.

Nassif, F. B. (2017). A tecnologia LIDAR aplicada a medições eólicas sobre corpos hídricos e oceano (Dissertação de mestrado). Programa de Pós-graduação em Engenharia Mecânica, Universidade Federal de Santa Catarina, Florianópolis.

Peña Diaz, A., Hasager, C. B., Gryning, S., Courtney, M., Antoniou, I., \& Mikkelsen, T. (2009). Offshore wind profiling using light detection and ranging measurements. Wind Energy, 12(2), 105-124. http://dx.doi.org/10.1002/we.283.

Peña Diaz, A., Mikkelsen, T., Gryning, S. E., Hasager, C. B., Hahmann, A. N., Badger, M., Karagali, I., \& Courtney, M. (2012). Offshore vertical wind shear: final report on NORSEWInD's work task 3.1 (DTU Wind Energy E, No. 0005). Roskilde, Denmark: DTU Wind Energy.

Pimenta, F. M., \& Assireu, A. T. (2015). Simulating reservoir storage for a wind-hydro hydrid system. Renewable Energy, 76, 757-767. http://dx.doi.org/10.1016/j.renene.2014.11.047.

Pimenta, F. M., Silva, A. R., Assireu, A. T., Almeida, V. S., \& Saavedra, O. R. (2019). Brazil Offshore wind resources and atmospheric surface layer stability. Energies, 12(4195), 4195. http:/ / dx.doi.org/10.3390/en12214195.

Pitter, M., \& Woodward, A. (2015). Remote sensing on floating offshore platforms. Windtech.

Pitter, M., Slinger, C., \& Harris, M. (2013). Introduction of continous-wave doppler LIDAR. In DTU Wind Energy, Remote sensing for wind energy (DTU Wind Energy-E-Report-0029(EN), pp. 72-103). Roskilde, Denmark: DTU Wind Energy.

Pryor, S. C., \& Barthelmie, R. J. (2001). Comparison of potential power production at on- and offshore sites. Wind Energy, 4(4), 173-181. http://dx.doi.org/10.1002/we.54.

Rodrigues, S., Restrepo, C., Kontos, E., Pinto, R. T., \& Bauer, P. (2015). Trends of offshore wind projects. Renewable \& Sustainable 
Energy Reviews, 49, 1114-1135. http://dx.doi.org/10.1016/j. rser.2015.04.092.

Said, L., Sheng, L., Farouk, N., \& Latifa, B. (2012). Modeling, design and control of a ship carried 3 DOF stabilized platform. Journal of Applied Sciences, Engineering and Technology, 4(19), 3843-3851.

Standridge, D., Zeitler, D., Nieves, Y., Turnage, T. J., \& Nordman, E. E. (2012). Validation of a buoy-mounted laser wind sensor and deployment in Lake Michigan: technical report (15 p.). Michigan: Grand Valley State University.

Tiana-Alsina, J., Gutiérrez, M. A., Würth, I., Puigdefàbregas, J., \& Rocadenbosch, F. (2015). Motion compensation study for a floating doppler wind LIDAR. In 2015 IEEE International Geoscience and Remote Sensing Symposium (IGARSS) (pp. 5379-5382). New York: IEEE. http://dx.doi.org/10.1109/IGARSS.2015.7327051.

U. S. Army Corps of Engineers - USACE. (2002). CEM-US ACE: Coastal Engineering Manual: Part II: Coastal Hydrodynamics: EM 11102-1100 (624 p). Washington.

Weitkamp, C. (2006). LIDAR: range-resolved optical remote sensing of the atmosphere. New York: Springer-Verlag.

Wissemann, C. (2009). Offshore wind energy meeting presentation. Rutgers University, IOOS.
Yamaguchi, A., \& Ishihara, T. (2015). Floating offshore wind measurement system by using LIDAR and its verification. In EWEA 2015 Annual Event Proceedings. Red Hook, NY: Curran Associates.

Zephir. (2014). Zephir 300 Operations \& Maintenance Manual V3.8 (65 p.).

\section{Authors contributions}

Felipe Barros Nassif: Design and construction of estabilidar, fieldwork, data analysis and wrote the first version of manuscript.

Felipe Mendonça Pimenta: Design of estabilidar, methods, fieldwork, data analysis, writing and review of manuscript. Provided equipment and funding.

Arcilan Trevenzoli Assireu: Design and construction of the floating platform, coordination of fieldwork, writing and review. Provided equipment and funding.

Carla de Abreu D’Aquino: Analysis, writing and review.

Julio César Passos: Construction of estabilidar, writing and review, provided equipment. 